\title{
Expressed emotion (EE) in families of individuals at-risk of developing psychosis: A systematic review
}

DOI:

10.1016/j.psychres.2018.10.065

\section{Document Version}

Accepted author manuscript

Link to publication record in Manchester Research Explorer

\section{Citation for published version (APA):}

Izon, E., Berry, K., Law, H., \& French, P. (2018). Expressed emotion (EE) in families of individuals at-risk of developing psychosis: A systematic review. Psychiatry Research, 270, 661-672.

https://doi.org/10.1016/j.psychres.2018.10.065

\section{Published in:}

Psychiatry Research

\section{Citing this paper}

Please note that where the full-text provided on Manchester Research Explorer is the Author Accepted Manuscript or Proof version this may differ from the final Published version. If citing, it is advised that you check and use the publisher's definitive version.

\section{General rights}

Copyright and moral rights for the publications made accessible in the Research Explorer are retained by the authors and/or other copyright owners and it is a condition of accessing publications that users recognise and abide by the legal requirements associated with these rights.

\section{Takedown policy}

If you believe that this document breaches copyright please refer to the University of Manchester's Takedown Procedures [http://man.ac.uk/04Y6Bo] or contact uml.scholarlycommunications@manchester.ac.uk providing relevant details, so we can investigate your claim.

\section{OPEN ACCESS}




\section{Accepted Manuscript}

Expressed Emotion (EE) in families of individuals at-risk of developing psychosis: A Systematic Review

Emma Izon, Katherine Berry, Heather Law, Paul French

PII:

DOI:

S0165-1781(18)31045-X

Reference: https://doi.org/10.1016/j.psychres.2018.10.065 PSY 11841

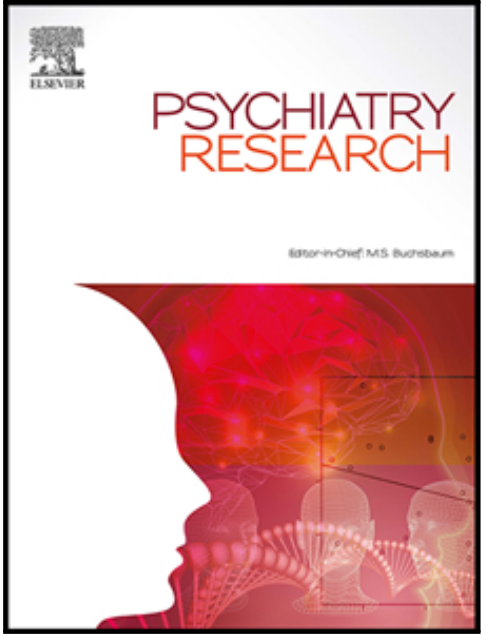

To appear in:

Psychiatry Research

Received date:

6 June 2018

Revised date:

24 October 2018

Accepted date:

24 October 2018

Please cite this article as: Emma Izon, Katherine Berry, Heather Law, Paul French, Expressed Emotion (EE) in families of individuals at-risk of developing psychosis: A Systematic Review, Psychiatry Research (2018), doi: https://doi.org/10.1016/j.psychres.2018.10.065

This is a PDF file of an unedited manuscript that has been accepted for publication. As a service to our customers we are providing this early version of the manuscript. The manuscript will undergo copyediting, typesetting, and review of the resulting proof before it is published in its final form. Please note that during the production process errors may be discovered which could affect the content, and all legal disclaimers that apply to the journal pertain. 


\section{Highlights}

- High levels of criticism, hostility, warmth and EOI were found in the ARMS group.

- Levels of high-EE in ARMS were similar to that of FEP.

- More criticism and hostility was linked with poorer functioning and worse symptoms.

- Warmth and optimal family involvement improved functioning and reduced symptoms.

- High criticism and EOI negatively impacted family member's health

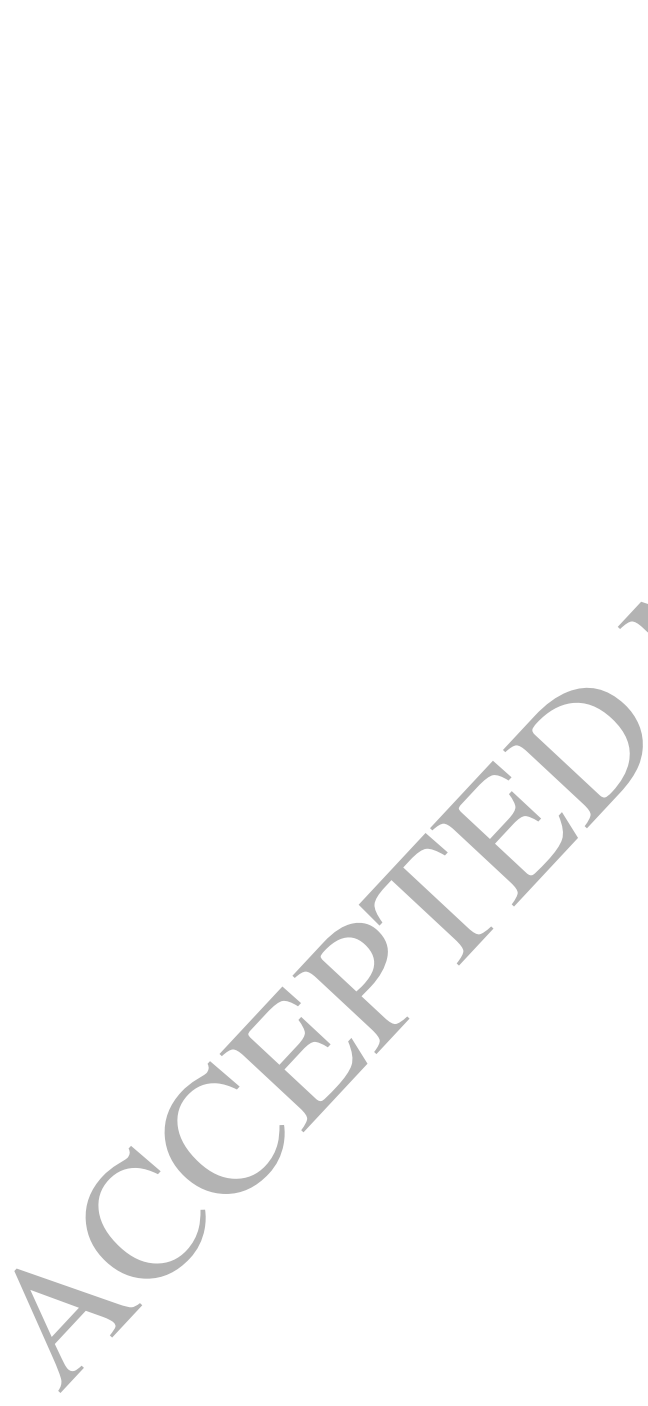




\title{
Expressed Emotion (EE) in families of individuals at-risk of developing psychosis: A Systematic Review
}

\author{
Emma Izon $^{\text {ab }}$, Katherine Berry ${ }^{\mathrm{a}}$, Heather Law ${ }^{\mathrm{b}}$, Paul French ${ }^{\mathrm{ab}}$
}

${ }^{a}$ Division of Psychology and Mental Health, The University of Manchester, Manchester, United Kingdom

${ }^{\mathrm{b}}$ Greater Manchester Mental Health NHS Foundation Trust, Manchester, United Kingdom

*Corresponding author

Postal address: Psychology Department, Harrop House, Prestwich Hospital, Manchester, M25 3BL

Telephone: 01613582140 Fax: 01617724351

Email: emma.izon@gmmh.nhs.uk / emma.izon@postgrad.manchester.ac.uk 


\begin{abstract}
The At-Risk Mental State (ARMS) for psychosis describes a state of high but not inevitable risk for developing a psychotic disorder. The distressing experiences for individuals with an ARMS may impact on themselves; their sense of wellbeing, psychosocial functioning and their family. Expressed emotion (EE) considers the environment and communication style of relatives towards the individual and is a key factor for determining outcomes in established psychosis. Following PRISMA guidelines, a systematic review of EE in relatives of ARMS was conducted. Fifteen studies were identified that investigated the presence of EE in the ARMS population. Approximately one third of ARMS relatives had high-EE. The results suggest that greater levels of criticism are associated with higher levels of symptoms and poorer functioning. In contradiction to psychosis literature, the construct emotional-over-involvement was found to be an adaptive response, where an optimal level of involvement combined with a warm-environment was associated with improved functioning and reduced symptoms. Limitations of the studies include small sample sizes and over-representation of Caucasian males and relatives as middle-aged mothers. Although approximately half of the studies included were longitudinal, only two measured EE over time, therefore, future research should include larger studies measuring $\mathrm{EE}$ at different timepoints.
\end{abstract}

Key words: Clinical risk; psychosis; expressed emotion; relationships.

Abbreviations: At-Risk Mental State (ARMS); EE (Expressed Emotion). 


\section{Introduction}

Individuals vulnerable to a psychotic disorder are identified as having an At-Risk Mental State (ARMS) for psychosis, falling into one or more of three possible groups: vulnerability factor (have a schizotypal personality disorder or a first-degree relative with a psychotic disorder), Attenuated Psychotic Symptoms (APS; sub-clinical psychotic symptoms), or Brief Limited Intermittent Psychotic Symptoms (BLIPS; full-blown psychotic symptoms that resolve themselves spontaneously within a week), in addition to either chronic low functioning or a $30 \%$ drop within the past year. The rate of conversion from ARMS to psychosis is approximately $20 \%$ in the first year, increasing steadily over subsequent years, whilst $40 \%$ of individuals still meet ARMS criteria after 6-months (Tor et al., 2017).

Expressed Emotion (EE) refers to the quality of the family environment reflected in the comments, attitudes and communication style of a relative about an individual. It has been well established as a reliable psychosocial predictor of symptom relapse in a wide range of mental health conditions, including psychosis (Butzlaff and Hooley, 1998). The construct of EE comprises of the following patterns/behaviours: negative aspects of criticism, hostility and emotional-over-involvement (EOI) and positive aspects of warmth and positive remarks (Leff and Vaughn, 1985). When individuals live in a family environment characterised by critical, hostile or emotional overinvolved or intrusive attitudes (high-EE environments) they are at a higher risk of early relapse compared to individuals who do not live in these environments (Butzlaff and Hooley, 1998; Hooley and Campbell, 2002). Some researchers have discussed these components as reactions to the recent symptoms: criticism and hostility describe more angry attempts of the carer to force the individual into normative behaviours, whereas EOI marks their awareness that the condition and health status is deteriorating and reflects more over concern (Hooley and Campbell, 2002). Limited research has investigated these different reactions and their long-term impact on symptoms in the ARMS population. EE is of interest to researchers and clinicians but they often focus their attention upon negative aspects and high-EE despite positive components being of potentially equal importance.

There are many instruments that can be used to assess the family environment in terms of EE. These assessment tools can be completed by either the patient or their family member. Participants can complete these themselves through self-report questionnaires or take part in an audio-recorded interview, such as the Camberwell Family Interview (CFI), the gold- 
standard measure for EE from the relative's perspective. Examples of different assessment tools can be seen in table 1 .

Table 1. An overview of different methods and tools used to assess EE

\begin{tabular}{llll}
\hline \multicolumn{1}{c}{$\begin{array}{c}\text { Questionnaire / } \\
\text { Interview }\end{array}$} & \multicolumn{1}{c}{ Rater } & Type of participant & Examples of measure \\
\cline { 3 - 4 } $\begin{array}{l}\text { Interview } \\
\text { Questionnaire }\end{array}$ & $\begin{array}{l}\text { Researcher / clinician } \\
\text { Participant }\end{array}$ & $\begin{array}{l}\text { Relative / Family Member } \\
\text { Relative / Family Member }\end{array}$ & $\begin{array}{l}\text { CFI, FMSS } \\
\text { The FQ,FMPC, }\end{array}$ \\
Questionnaire & Participant & Patient / Individual & FMPW, SAS-III, FAS \\
& & & PC, PW, LEE, FPS, \\
& & BDSEE \\
\hline
\end{tabular}

Abbreviations: BDSEE: the Brief Dyadic Scale of Expressed Emotion; CFI: Camberwell Family Interview; FAS: Family Attitude Scale; FMSS: The Five Minute Speech Sample; FMPC: Family Member Perceived Criticism Questionnaire; FMPW: Family Member Perceived Warmth Questionnaire; FPS: Family Perception Scale; LEE: Level of Expressed Emotion; PC: Perceived Criticism Questionnaire; PW: Perceived Warmth Questionnaire; SAS-III: Social Adjusting Scale III; The FQ: The Family Questionnaire.

$\mathrm{EE}$ is linked to outcomes across a range of physical and mental health conditions, including psychosis (Butzlaff and Hooley, 1998; Hooley, 2007). Individuals with established psychosis are more likely to relapse and have poorer prognosis, whilst living in high-EE environments (Stafford et al., 2015). It is important to note that levels of EE have been found to vary across cultures and socio-ethnic backgrounds (Bhugra and McKenzie, 2003; López et al., 2009), as well as depending of the stage of the patient's illness (Gómez-deRegil et al., 2014). For example, in psychosis literature high levels of EOI were found in the families of British Pakistanis (Muslims) compared to British Sikh and White families, however, EE did not predict relapse for either Asian population (Hashemi and Cochran, 2009). A systematic review found that components of EE may vary across families from different cultural backgrounds, thus impacting how families respond to the individual's condition and influencing the likelihood of relapse and other outcomes (Singh et al., 2013).

Previous studies have indicated that within the psychosis population, high-EE is a predictor of relapse and rehospitalisation. Several studies have explored the needs, perceptions and mental health of carers supporting these individuals and found that high-EE is associated with high carer burden (Wang et al., 2017). Family members experiencing high burden were more likely to have higher levels of anxiety and depression and financial impairment (Barrowclough et al., 1996; Jansen et al., 2015). Levels of family burden (both subjective 
and objective) have found to be similar in ARMS and recent-onset psychosis individuals, with the amount of worry reported equivalent to that of chronic psychosis (Wong et al., 2008). Understanding whether high-EE effects ARMS family members' health and wellbeing would be important for services and clinicians when providing treatment.

Family interventions (FI) targeting high-EE improve long-term outcomes in established psychosis (Pharoah et al., 2010). Similarities between ARMS and established psychosis suggest that FI could have a similar impact on the ARMS population. Recommended treatment for ARMS individuals in England is individual Cognitive Behavioural Therapy (CBT) with or without family intervention (NICE, 2014). However, the recommendation for FI is based on expert opinion not robust empirical evidence. Understanding the nature of EE, the different components and differences dependent on one's stage of illness could aid clinicians and services to provide targeted treatment according to the phase of illness and ARMS needs.

There is limited family intervention research in ARMS, but there has been a growth of literature in the EE concept in this population, looking to establish the presence or effect of high-EE. It is important to synthesise the growing body of knowledge, to determine the extent to which we need to assess EE in ARMS families and intervene through the use of FI specifically targeting EE.

\subsection{Aims}

1. Examine the rates of high-EE, as well as the five sub-components of EE (criticism, hostility, EOI, warmth and positive statements) and their impact on the individual and their family member.

2. Compare EE in the ARMS population with healthy controls and established psychosis, both First Episode Psychosis (FEP) and chronic psychosis.

3. Review whether a family intervention targeting high-EE or the specific components would be important and helpful for ARMS individuals and their families.

4. Highlight the limitations within the field and identify clinical interventions and recommendations for future practice and research.

\section{Method}

\subsection{Search Strategy}


This review was conducted in line with PRISMA guidelines for reporting systematic reviews (Moher et al., 2009). The published review protocol can be found on PROSPERO https://www.crd.york.ac.uk/PROSPERO/display_record.asp?ID=CRD42017064927). ${ }^{1}$

An electronic advanced search was carried out on four databases PsycINFO, EMBASE, PubMed and Web of Science using the following keywords: "at risk mental state" OR "ultra high risk” OR "UHR” OR “clinical high risk” OR “CHR” OR "prodrom*” AND “psychos*” OR "psychot*” OR “schizo*” AND "Expressed Emotion” OR "EE” OR “emotional*” OR “warm*” OR “ hostil*” OR “critic*”. These searches were limited to human and English language. The references in each included paper were reviewed by hand (through backwards searching), cited papers were reviewed online (through forwards searching) for extra relevant publications not have been identified in the initial electronic search. Until the review was ready to be submitted for publication $(30 / 08 / 2018)$, the four databases were regularly checked.

\subsection{Inclusion Criteria}

Eligible studies were original research papers, published in peer-reviewed journals, in English, using populations that met the ARMS criteria on a validated instrument. Individuals with an ARMS aged between 11-35 years were included. Studies that included a validated measure of EE and ARMS were deemed necessary to ensure construct reliability. Intervention studies that examined EE pre- and post-intervention were eligible as were cross-sectional studies investigating correlates of EE.

\subsection{Exclusion Criteria}

In England, Early Detection and Intervention Teams (EDIT) are preventative services for young people (aged 14-35) at high-risk of developing psychosis. Through the initial scope of the literature, we found a proportion of studies (typically American) included individuals from age 11 upwards. To avoid missing findings from this literature, we lowered the inclusion criterion to age 11 years. The search was restricted to English language journal articles as none of the authors were deemed fluent in another language.

\subsection{Study Selection and data extraction}

\footnotetext{
${ }^{1}$ The age range states $12-35$ on the inclusion criteria protocol. This was changed to 11-35 within the systematic review as a key paper was identified with the lower age range.
} 
The initial search retrieved 2,897 citations, removal of duplicates left 2,235 and 2,212 were excluded at title stage as inconsistent with the review topic. Article abstracts were screened for eligibility by the first author and an independent researcher, with a high-level of agreement $(K=0.897)$. Disagreements were resolved through discussion and consensus with additional review team members (P.F and K.B). The first author screened 23 full-texts of the remaining articles, 8 were excluded due to an inadequate measure of $\mathrm{EE}(n=5)$ or no peerreview $(n=3)$. No additional papers were identified from reviewing reference lists. Fifteen papers met full inclusion criteria and a data extraction tool was developed to record: (1) Study characteristics (authors, year of publication, country where the work was performed; study design); (2) Sample demographics for patients (sample size, gender composition, mean age); (3) Sample demographics for family members (sample size, caregiver gender composition); (4) The at-risk screening instrument used to assess eligibility; (5) EE measure(s) used; (6) Summary of study findings. For intervention studies, the intervention and comparator ARMS and treatment duration were also recorded.

\subsection{Quality Assessment Tool}

Each paper was critically appraised using the Appraisal tool for Cross-Sectional Studies (AXIS; Downes et al., 2016), looking at each aspect of the study without enforcing a numerical scale, which can be problematic as the assessment checklists are not linear (Jüni et al., 1999). Of the included papers, $80 \%$ were reviewed by both the first author and a postgraduate researcher to assess inter-rater reliability. The level of agreement for total scores was over $80 \%$ agreement in the overall proportion of papers, with discrepancies resolved through discussion. 


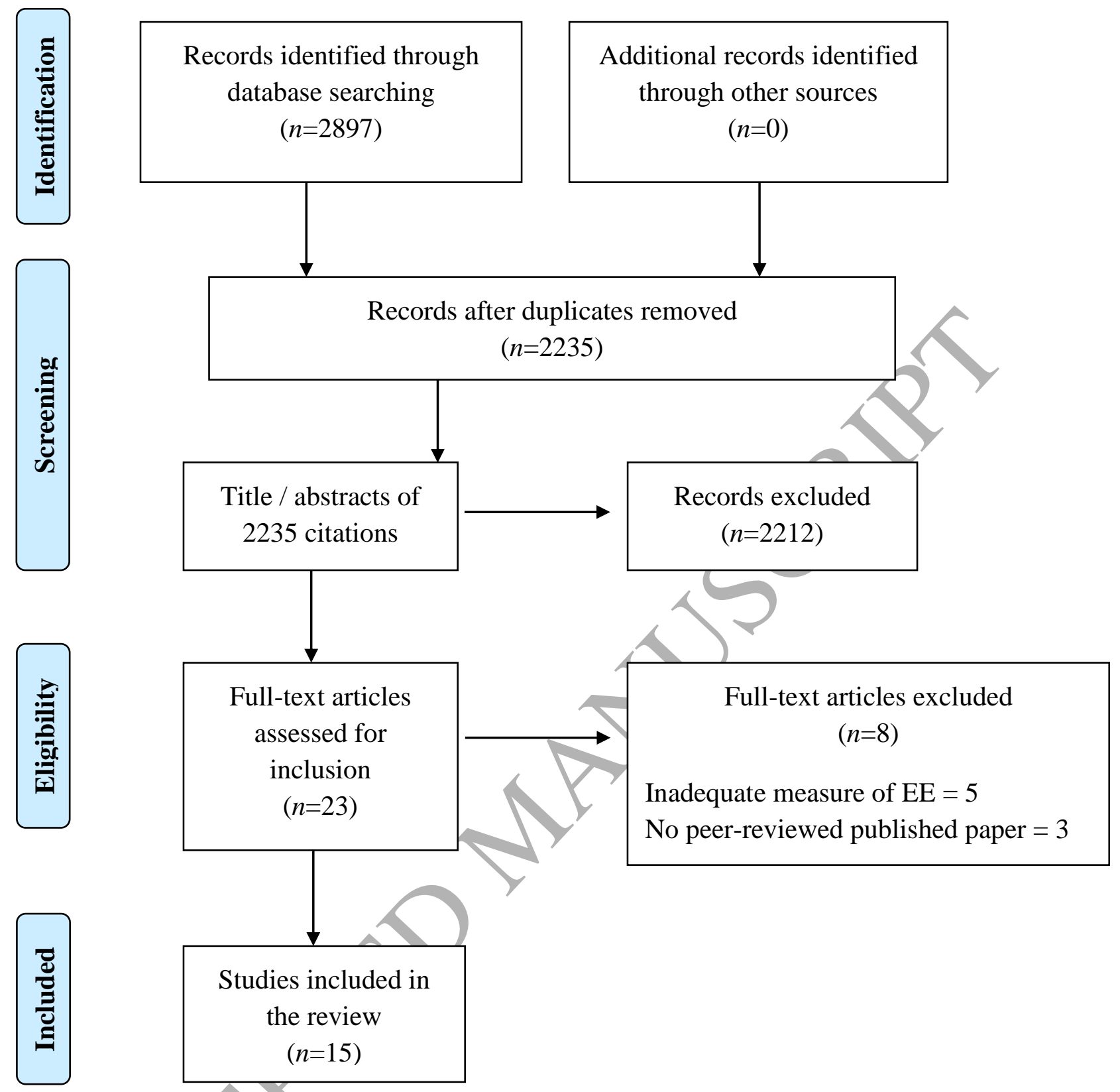

Figure 1 PRISMA flow diagram of systematic search

\section{Results}

\subsection{Overview of the studies}

The studies were conducted in America ( $n=9)$, Europe $(n=5)$ and Asia $(n=1)$, comprising cross sectional $(n=8)$ and longitudinal $(n=7)$ designs. Only two longitudinal studies compared EE at different time points (Golembo-Smith et al., 2014; O'Brien et al., 2015), the others examined how EE affected symptoms or functioning over time. There were three different measures of ARMS; the Structured interview for Prodromal Symptoms (SIPS; $n=10$ ), the Comprehensive Assessment of and At-Risk Mental State (CAARMS; $n=4$ ) and the Personal Assessment and Crisis Evaluation (PACE; $n=1$ ). Eleven different measures 
were used to assess EE that included interview measures rated by the researchers and completed with the caregiver $(n=6)$, self-report questionnaire measures completed by either the caregiver $(n=7)$ or the individual $(n=6)$. Four studies included more than one measure of EE (Golembo-Smith et al., 2014; O'Brien et al., 2015; Schlosser et al., 2010; Tsai et al., 2015), of which three studies included subjective EE measures completed by both caregivers and individuals (Golembo-Smith et al., 2014; O'Brien et al., 2015; Schlosser et al., 2010).

Most studies included a male, Caucasian majority. Fourteen studies consisted of ARMS individuals with a mean age below 24 years, with the majority of studies below 17 years $(n=9)$. The majority of individuals fell into APS group on the ARMS criteria.

Often relatives were first degree and typically mothers. Four studies reported on the age of the family member, with a mean age ranging between 48-51 years. Carers' mean years in education ranged from 13-16 years with college degree typically the highest level, although varying dependent on ethnic background.

Table 2. Summary of the fifteen included studies looking at Expressed Emotion (EE) in the ARMS population

\subsection{Quality Assessment Tool}

The majority of the studies provided clear aims, well described results and acknowledged their limitations but there was limited information on the rationale for the sample size, power calculation or information about participants initially screened for the study.

Table 3. Quality review of the included studies

3.3. Examine the rates of high-EE, as well as the five sub-components of EE (criticism, hostility, EOI, warmth and positive statements) and their impact on the individual and their family member.

Rates of high and low-EE were reported in three studies (Meneghelli et al., 2011; O'Brien et al., 2006; Schlosser et al., 2010). O'Brien et al (2006) found 35\% of high-EE in the sample, typically from critical comments, whilst Schlosser et al. (2010) found 31.1\% families had high-EE, typically from hostile comments (68\%). Meneghelli et al. (2011) found 33.3\% of ARMS caregivers reported high-EE, typically from EOI. They found ARMS patients with 
high-EE caregivers were on average significantly younger than low-EE caregivers, had higher contact and lived with the individual. These studies had high quality with all three studies maintaining over $90 \%$ retention rate at follow-up; with baseline EE measured by the gold standard Camberwell Family Interview (CFI). Unfortunately, no study looked at change in high-EE over time.

\subsection{EE Components:}

\subsubsection{Criticism}

All fifteen papers measured criticism. Eight found negative forms of criticism worsened symptoms and functioning (O’Brien et al., 2006; 2009; 2015; Schlosser et al., 2010; Welsh and Tiffin, 2015; Domínguez-Martínez et al., 2014; McFarlane and Cook, 2007; Tsai et al., 2015). Tsai et al. (2015) found an effect of ethnicity and gender for criticism: Individuals with critical Latino fathers had more negative symptoms than non-Latino white fathers, albeit with a small sample size. Three studies found no association between symptoms, functioning and criticism (Meneghelli et al., 2011; Hamaie et al., 2016; Golembo-Smith et al., 2014). Meneghelli et al. (2011) found that the individual's gender, functioning and suicidal and self-harm behaviours had no impact on levels of EE. These differences may be explained by the education level of the ARMS carer, the age of the individual or cultural, ethnic or religious differences between the samples.

\subsubsection{Hostility}

Six studies measured hostility (O'Brien et al., 2006; 2008; 2009). One reported ARMS families were more likely to have higher levels of hostility compared to healthy controls (Welsh and Tiffin, 2015), whilst on average parents reported more EOI and positive remarks than critical, hostile or warm comments (Meneghelli et al., 2011). Schlosser et al. (2010) found $68 \%$ of the high-EE caregivers exhibited hostility. Hostility predicted $15 \%$ of the variance of change in worsening of positive symptoms over time. This study has $93.65 \%$ retention rate at 6-month follow-up, EE measures completed by both patient and family member and an interview with the family member. However, $8 \%$ of the sample experienced recent-onset symptoms (within the last 3-months) that reached a psychotic FEP intensity. It is difficult to draw comparisons between the studies as Welsh and Tiffin's Family Perception Scale (FPS) was validated by the first author, whilst the other studies used the gold standard CFI to measure EE. 


\subsubsection{Emotional-Over-Involvement (EOI)}

Eight studies measured EOI, four reporting moderate-high rates of reported comments compared to other EE components (McFarlane and Cook, 2007; O'Brien et al., 2006; Domínguez-Martínez et al., 2014; Meneghelli et al., 2011). Meneghelli et al. (2011) found mothers reported more EOI and positive remarks than critical, hostile or warm comments. They found a tendency for high EOI to be comments regarding concern and worry over the individual's well-being and condition rather than self-sacrifice and dysfunctional overprotection. This study has high quality having interviewed both mothers and fathers and using the CFI to measure EE but the study used a cross sectional design with a small and predominantly male sample.

\subsubsection{Warmth}

Nine studies measured warmth, three finding warmth predicted increased social functioning (O’Brien et al., 2008; 2009; Schlosser et al., 2010), was positively correlated with problem solving skills (O’Brien et al., 2009) and protectiveness (McFarlane and Cook, 2007). Highlevels of warmth by caregivers were associated with reductions in symptoms at 3 and 6month follow up (O’Brien et al., 2006; Schlosser et al., 2010), with a lack of warmth associated with increased negative statements (Carol and Mittal, 2015) and rejection (McFarlane and Cook, 2007). Tsai et al. (2015) found ethnicity moderated the relationship of warmth and symptoms. Higher warmth from non-Latino white mothers and fathers of an ARMS individual was associated with lower positive and negative symptomology, higher warmth was associated with higher levels of symptomology for the Latino population. However, only 11 Latino adolescents took part and the authors did not interview the family members, nor look at the impact and effect of EOI, which may have affected the relationship

\subsubsection{Positive Comments}

Six studies measured positive remarks, five used the CFI and one the Five Minute Speech Sample (FMSS). Only two looked at the amount of positive comments reported. O'Brien et al. (2006) reported the mean positive remarks on the CFI as 2.7, which rated slightly higher than critical comments and EOI, but lower than warmth. Meneghelli et al. (2011) found parents reported more EOI and positive remarks than critical, hostile or warm comments. Cultural differences of the samples could explain this difference; possibly Italian families are less likely to want to disclose negative emotional matters to strangers. Positive remarks 
positively associated with problem solving skills (O'Brien et al., 2009), constructive behaviour (O’Brien et al., 2008), decreased negative symptoms (O’Brien et al., 2006; 2008; Carol and Mittal, 2015) and a weak trend of fewer positive remarks and EOI associated with increased positive symptoms (Carol and Mittal, 2015). All studies looked only at correlations.

Two studies found EOI and high levels of warmth predicted enhanced functioning and reduction in symptoms (O'Brien et al., 2006; Schlosser et al., 2010), with lower warmth less likely to change functioning regardless of the levels of EOI. Three studies found positive communication (warmth, positive remarks and EOI) and perceptions predicted improvements in negative symptoms and/or social functioning (O’Brien et al., 2006; 2008; Tsai et al., 2015) suggesting the importance of warmth, positive remarks and optimal EOI in improving functioning and symptoms.

\subsubsection{Impact on the Family Members}

Three studies looked at the effect of EE on relatives' health. Family members reported varying levels of depression with the average reported scores suggesting mild symptoms of depression (Welsh and Tiffin, 2015), whilst one study found one third of carers of reported mild-moderate depression (Hamaie et al., 2016). Domínguez-Martínez et al. (2017) found criticism and EOI strongly associated with relatives' distress, illness attributions, anxiety and depression. The consistency of the result suggests the finding is reliable.

\subsection{Compare EE in the ARMS population with healthy controls and established psychosis} (both FEP and chronic psychosis).

Two studies compared EE in ARMS populations with healthy controls (Welsh and Tiffin, 2015; Carol and Mittal, 2015). Welsh and Tiffin (2015) also included a psychosis group, finding the clinical population had significantly higher-EE compared to the control population, with ARMS relatives perceiving greater, but non-significant family dysfunction compared to psychosis group. Carol and Mittal (2015) found no differences between ARMS and control population in either critical comments or EOI. Caregivers of ARMS population provided fewer initial positive statements, suggesting a moderate trend. Both studies found lower levels of warmth in ARMS compared to healthy controls (Carol and Mittal, 2015; Welsh and Tiffin, 2015). 
Differential rates of EE were found between ethnic groups and dependent on the patient's stage of illness. High-EE for FEP caregivers was between 30-40\% (Meneghelli et al., 2011; Domínguez-Martínez et al., 2014), similar to caregivers of the ARMS population (Meneghelli et al., 2011; Schlosser et al., 2010; O’Brien et al., 2006), but lower than chronic psychosis (McFarlane and Cook, 2007). Although Tsai et al. (2015) found higher-EE in Latino ARMS groups compared to psychosis literature, possibly due to cultural differences and small sample size. Only one study (Tsai et al., 2015) included in this review investigated how ethnicity moderates the relationship between high-EE and ARMS symptomology. The authors acknowledge the limitations of this review's ability to provide a comprehensive overview on the relationship between the different EE components, ethnic groups and clinical outcomes for ARMS individuals, with scarce research in this area.

Two studies found the exhibited proportion of negative family perceptions similar for ARMS and FEP populations (Welsh and Tiffin, 2015; Hamaie et al., 2016), whilst Domínguez-Martínez et al. (2017) found caregivers of ARMS more critical than FEP caregivers. Domínguez-Martínez et al. (2014) investigated associations of criticism and EOI with symptoms in functioning in ARMS and FEP finding higher EOI related to symptom severity (negative and general psychopathology) and worse functioning in ARMS. When compared to schizophrenic populations, McFarlane and Cook (2007) found relatives of ARMS individuals were warmer, less rejecting, less protective and less fused with their child. These disagreements may be explained by the differences between demographics of the sample, including age, years in education, duration of illness, but questions of whether EE may appear secondary to onset of psychosis and progression toward chronic disability remains unclear.

\subsection{Review whether a family intervention targeting high-EE or the specific components} would be important and helpful for ARMS individuals and their families.

A cross-sectional study found longer duration of untreated illness (DUI) in the ARMS population positively correlated with higher levels of EE (McFarlane and Cook, 2007). Two studies investigated EE over time (Golembo-Smith et al., 2014; O'Brien et al., 2015), neither commenting on initial rates nor change in high or low-EE. Furthermore, both studies included a two question self-report of perceived criticism, therefore not accounting for other EE components. 
One Randomised Control Trial (RCT) looked at differences in EE pre and post-intervention (either three or 18 sessions of therapy) and its effect on EE within the ARMS population (O'Brien et al., 2015). They found after clinical intervention (at 6-month follow-up), maternal criticism significantly reduced in ARMS, with a significant effect of time. Patients' perceived criticism between baseline and 6-months predicted improvements in positive symptoms at 12-month follow-up, over and above improvements in symptoms at 6-months. Therefore, reduced criticism following intervention led to improvements in positive symptoms. However, the retention rate at 6 -months was below $50 \%$ in both groups seriously affecting validity of findings.

One study investigated transition to psychosis (Haidl et al., 2018), the majority ( $n=9)$ had low sample sizes and lack of power to establish EE as a predictor of transition. Haidl et al. (2018) assessed 235 individuals at baseline, 179 at 18-months, finding criticism and EOI irrelevant in predicting increased risk of transition to psychosis. They found "perceived irritability" of the most important person in their social environment a predictor of conversion for ARMS to FEP. This improved prediction above 0.90 (Haidl et al., 2018) in The European Prediction of Psychosis Study (EPOS) model. Therefore, negative perceptions of the main carer from individuals with an ARMS appear to increase their risk of transitioning to psychosis.

\section{Discussion}

\subsection{Summary of findings}

Approximately one third of ARMS relatives had high-EE, similar to individuals with FEP, although significantly lower than long-term psychosis (Meneghelli et al., 2011; O'Brien et al., 2006; Schlosser et al., 2010). All aspects of EE were found within the ARMS population. Greater levels of criticism and hostility were associated with higher levels of symptoms and poorer functioning (O’Brien et al., 2006; 2009; 2015; Schlosser et al., 2010; Welsh and Tiffin, 2015; Domínguez-Martínez et al., 2014; McFarlane and Cook, 2007; Tsai et al., 2015). EOI was found with family members' reporting statements of concern and worry for the individual, whilst making no impact on individuals' symptoms (Meneghelli et al., 2011). Warmth was highly reported compared to other components of EE and when warm environments were combined with optimal family involvement individuals functioning improved over time and symptoms reduced (O'Brien et al., 2008; 2009; 
Schlosser et al., 2010). High criticism and EOI impacted on family member's health through increasing levels of depression (Welsh and Tiffin, 2015; Hamaie et al., 2016), as well as causing increased levels of distress and anxiety (Domínguez-Martínez et al.,2017). One study found that family intervention, such as psychoeducation reduced criticism and predicted improvements of patients' symptoms (O’Brien et al., 2015).

The review includes different measures in assessing EE, comprising of interviews with caregivers that are rated by the researchers, and self-report questionnaires completed by either the caregiver or the individual. Self-report questionnaires have the advantage of being quick and relatively easy to complete, although interviews provide a more detailed description and enable researchers to analyse all of the components of EE. The impact of different informants and measures in assessing EE makes it difficult to establish a general consensus across the findings. However, including both informants and having the opportunity to ask either one about their perceptions may provide a more detailed picture of the family environment and a more inclusive and alternative methods in assessing the EE.

Levels of criticism varied, some finding higher levels of criticism comments compared to FEP carers (Domínguez-Martínez et al., 2014; 2017), possibly explained by caregivers' uncertainty and confusion surrounding the ARMS condition, further impacting on their own health and induce stress (Domínguez-Martínez et al., 2017). Family members may reduce criticism over time naturally as they adjust to the individuals symptoms (O'Brien et al., 2015), which may differ from psychosis literature, where criticism has been found to increase relative to the person's symptoms and condition (Hooley and Ritchers, 1995). This suggests that criticism may be associated with the family members' appraisal rather than the psychotic symptomology for ARMS.

High levels of worry were found at a similar rate when comparing ARMS and recent-onset psychosis individuals, with the amount of worry reported equivalent to that of chronic psychosis (Wong et al., 2008).Considering the ARMS population are at the onset of the condition, one may expect to see high EOI in parents, with high levels of protectiveness, warmth and worry when symptoms are first noticed. Domínguez-Martínez et al. (2014, p.52) discuss EOI as a "protective factor" and a positive effects on the patient's outcome, specifically when combined with warmth. This may be an adaptive response leading to 
improvements in long-term functioning for ARMS individuals' (Schlosser et al., 2010; O’Brien et al., 2006).

Psychosis literature found that high-EE was associated with both higher carer burden and distress in family members' health (Wang et al., 2017; Jansen et al., 2015). Considering that family members of ARMS reported high levels of worry and concern (Wong et al., 2008), one may expect to see high-EE have a negative impact for ARMS families' health. Domínguez-Martínez et al. (2017) found that high levels of EOI were associated with a negative impact on family members' health and suggested that this may be due to family members overall concern, lack of understanding and general confusion in understanding their loved one's condition. It is worth noting that family member's lack of understanding and general confusion may depend and be mediated by their culture, education and access to health care.

\subsection{Limitations and future research}

Small sample size is a major issue and only two studies measured EE at follow-up. The EPOS model suggests perceived irritability of a key relative to be most important and the key predictor of conversion for ARMS to FEP, whereas neither criticism nor EOI were significant predictors (Haidl et al., 2018). In comparison to the other studies included in this review, only patients' experiences were measured, which may suggest a biased perception.

O'Brien et al. (2006, p.274) claimed that "the evaluation of only one key relative for each patient allows significant contributions to the family atmosphere to remain unaccounted for". The majority of caregivers were identified as first degree relatives, typically the mother. Haidl et al. (2018) found mothers were chosen as the most influential person by a higher but non-significant proportion of individuals who transitioned to psychosis. Two studies (Tsai et al., 2015; McFarlane and Cook, 2007) examined differences in EE between mothers and fathers. These limitations illustrate that the key carer may be overgeneralised and over-representative for this population.

The authors cannot guarantee that no non-English language studies investigated EE in families of ARMS or that any results would be consistent or conflicting to this review. Despite the limitations mentioned, this review included studies of varying methodologies for EE, including objective and subjective measures for both individual and caregiver's 
assessment of the perceived family environment. Measuring multiple perspectives of different people's perceptions provides a more reliable and valid outcome of the family environment. Including both individual and family members' perceptions, as well as independent observations of the relatives' behaviour and comments could provide more valid findings on the different EE components within the social environment. This would help provide an overall perception of the environment to clinicians whilst highlighting any discrepancies of viewpoint between the patient and their carer.

Recommendations for future research include larger sample sizes with combinations of interview questions and self-report measures of $\mathrm{EE}$ for caregiver and the individual to increase validity. High-EE remains the focus, typically examining criticism and EOI. Studies that examine positive affect may help improve our understanding of mental health outcomes for people at-risk of psychosis. Future research should look to investigate whether psychosocial treatment interventions that focus on psychoeducation and family coping strategies result in enhanced family support, facilitate positive behaviour and lead to improvements of long-term health and functioning for both individuals and their families.

\subsection{Clinical Implications}

The inclusion of an EE measurement in routine services with either the carer or patient or both would look to engage different types of families and increase clinicians' understanding of families' specific environments. Services would be able to provide targeted support to families to help them develop strategies and skills to minimise long-term high-EE attitudes, which has the potential to improve outcomes for individuals and their carers. Providing families with additional skills to create warm and encouraging environments, as well as provide psychoeducation, personalised to the individual's stage of psychosis and the caregivers' appraisal of the condition could help long-term outcomes for both the individual and their carer.

\subsection{Conclusion}

This is the first systematic review to synthesise the growing body of knowledge and to assess EE in ARMS families. Studying EE before and after people transition to psychosis (whilst in an ARMS) could help contribute to our understanding of how and why it develops in certain family systems and provide strategies to support high-EE families. Considering the vast research which suggests that the majority of ARMS individuals do not transition 
into psychosis, one might expect there to be significant differences between individuals with an ARMS and those with a diagnosis of a psychotic disorder. Comparing EE in ARMS individuals and those diagnosed with psychosis would contribute to our understanding of what factors are important in reducing $\mathrm{EE}$ at early-psychosis onset and changes in EE when people transition to psychosis.

\section{Conflict of Interest}

None

\section{Contributors}

EI, PF, KB and HL designed the review. EI performed the literature search, screened articles and extracted data from eligible sources. PF and KB confirmed articles eligible for inclusion. EI wrote the first draft of the manuscript. PF, KB and HL critically wrote and revised the manuscript. All authors approved the final manuscript.

\section{Role of funding source}

No funding sources.

\section{Acknowledgements}

The authors would like to thank Laura Collins, who kindly provided assistance during the screening of article abstracts and quality assessment.

\section{References}

Barrowclough, C., Tarrier, N., Johnston, M., 1996. Expressed emotion and attributions in relatives of schizophrenic patients. Schizoprenia Bulletin 22, 691-701.

Bhugra, D., McKenzie, K., 2003. Expressed emotion across cultures. Advances in Psychiatric Treatment 9 (5), 342-348.

Butzlaff, R.L., Hooley, J.M., 1998. Expressed emotion and psychiatric relapse: a metaanalysis. Archives of General Psychiatry 55 (6), 547-552.

Carol, E.E., Mittal, V.A., 2015. Resting cortisol level, self-concept, and putative familial environment in adolescents at ultra high-risk for psychotic disorders. Psychoneuroendocrinology 57, 26-36. 
Domínguez-Martínez, T., Medina-Pradas, C., Kwapil, T.R., Barrantes-Vidal, N., 2014. Relatives' illness attributions mediate the association of expressed emotion with early psychosis symptoms and functioning. Psychiatry Research 218, 48-53.

Domínguez-Martínez , T., Medina-Pradas, C., Kwapil, T.R., Barrantes-Vidal, N., 2017. Relatives' expressed emotion, distress and attributions in clinical high-risk and recent onset of psychosis. Psychiatry Research 247, 323-329.

Downes, M.J., Brennan, M.L., Williams, H.C., Dean, R.S., 2016. Development of a critical appraisal tool to assess the quality of cross-sectional studies (AXIS). British Medical Journal Open, https://doi.org/10.1136/bmjopen.2016.e011458.

Golembo-Smith, S., Bachman, P., Senturk, D., Cannon, T.D., Bearden, C.E., 2014. Youthcaregiver agreement on clinical high-risk symptoms of psychosis. Journal of Abnormal Child Psychology 42 (4), 649-658.

Gómez-de-Regil, L., Kwapil, T.R., \& Barrantes-Vidal, N., 2014. Predictors of expressed emotion, burden and quality of life in relatives of Mexican patients with psychosis. Journal of Psychiatric and Mental Health Nursing 21 (2), 170-179.

Haidl, T., Rosen, M., Schultze-Lutter, F., Nieman, D., Eggers, S., Heinimaa, M., et al., 2018. Expressed emotion as a predictor of the first psychotic episode - results of the European prediction of psychosis study. Schizophrenia Research, https://DOI.org/10.1016/j.schres.2018.03.019.

Hamaie, Y., Ohmuro, N., Katsura, M., Obara, C., Kikuchi, T., Ito, F., et al., 2016. Criticism and depression among the caregivers of at-risk mental state and first-episode psychosis patients. Public Library of Science, https://doi.org/10.1371/journal.pone.0156590.

Hashemi, A.H., Cochrane, R., 2009. Expressed emotion and schizophrenia: a review of studies across cultures. International Review of Psychiatry 11(2-3), 219-224. https://doi.org/10.1080/09540269974401

Hooley, J.M., 2007. Expressed emotion and relapse of psychopathology. Annual Review of Clinical Psychology 3, 329-352.

Hooley, J.M., Campbell, C., 2002. Control and controllability: beliefs and behaviour in high and low expressed emotion relatives. Psychological Medicine 32 (6), 1091-1099.

Hooley, J.M., Richters, J.E., 1995. Expressed emotion: a developmental perspective, in: Cicchetti, D., Toth, S.L. (Eds.), Rochester symposium on developmental psychopathology., New York, pp.133-166. 
Jansen, J.E., Haahr, U.H., Harder, S., Trauelsen, A.M., Lyse, H.G., Pedersen, M.B., et al., 2015. Caregiver distress in first-episode psychosis: the role of subjective appraisal, over-involvement and symptomatology. Social Psychiatry and Psychiatric Epidemiology 50 (3), 371-378.

Jüni, P., Witschi, A., Bloch, R.,.Egger, M., 1999. The hazards of scoring the quality of clinical trials for meta-analysis. The Journal of the American Medical Association 282 (11), 1054-1060.

Leff, J., Vaughn, C., 1985. Expressed Emotion in Families. Guilford Press, New York. López, S.R., García, J.I.R., Ullman, J.B., Kopelowicz, A., Jenkins, J., Breitborde, N.J.K., et al., 2009. Cultural variability in the manifestation of expressed emotion. Family Process 48 (2), 179-194.

McFarlane, W.R., Cook, W.L., 2007. Family expressed emotion prior to onset of psychosis. Family Process 46 (2), 185-197.

Meneghelli, A., Alpi, A., Pafumi, N., Patelli, G., Preti, A., Cocchi, A., 2011. Expressed emotion in first-episode schizophrenia and in ultra high-risk patients: Results from the Programma2000 (Milan, Italy). Psychiatry Research 189 (3), 331-338.

Moher, D., Liberati, A., Tetzlaff, J., Altman, D.G., Group., A.T.P., 2009. Preferred reporting items for systematic reviews and meta-analyses: The prisma statement. Annals of Internal Medicine 151 (4), 264-269.

NICE, 2014. Psychosis and schizophrenia in adults: Preventing psychosis. https://www.nice.org.uk/guidance/cg178/chapter/1-Recommendations\#preventingpsychosis-2 (accessed $13^{\text {th }}$ February 2018).

O'Brien, M.P., Gordon, J.L., Bearden, C.E., Lopez, S R., Kopelowicz, A., Cannon, T.D., 2006. Positive family environment predicts improvement in symptoms and social functioning among adolescents at imminent risk for onset of psychosis.

Schizophrenia Research 81, 269-275.

O'Brien, M.P., Miklowitz, D.J., Cannon, T.D., 2015. Decreases in perceived maternal criticism predict improvement in subthreshold psychotic symptoms in a randomized trial of family-focused therapy for individuals at clinical high risk for psychosis. Journal of Family Psychology 29 (6), 945-951.

O'Brien, M.P., Zinberg, J.L., Bearden, C.E., Lopez, S R., Kopelowicz, A., Daley, M., et al., 2008. Parent attitudes and parent adolescent interaction in families of youth at risk for psychosis and with recent-onset psychotic symptoms. Early Intervention in Psychiatry 2 (4), 268-276. 
O'Brien, M.P., Zinberg, J.L., Ho, L., Rudd, A., Kopelowicz, A., Daley, M.,et al., 2009. Family problem solving interactions and 6-month symptomatic and functional outcomes in youth at ultra-high risk for psychosis and with recent onset psychotic symptoms: A longitudinal study. Schizophrenia Research 107, 198-205.

Pharoah, F., Mari, J., Rathbone, J., Wong, W., 2010. Family intervention for schizophrenia. Cochrane Database Systematic Review, https://doi:10.1002/14651858.CD000088.pub2.

Schlosser, D.A., Zinberg, J.L., Loewy, R.L., Casey-Cannon, S., O'Brien, M. P., Bearden, C.E., et al., 2010. Predicting the longitudinal effects of the family environment on prodromal symptoms and functioning in patients at-risk for psychosis. Schizophrenia Research 118, 69-75.

Singh, S.W., Harley, K., Suhai, K., 2013. Cultural specificity of emotional overinvovlement: a systematic review. Schizophrenia Bulletin 39 (2), 449-463. https://doi.org/10.1093/schbul/sbr170.

Stafford, M.R., Mayo-Wilson, E., Loucas, C.E., James, A., Hollis, C., Birchwood, M., et al., 2015. Efficacy and safety of pharmacological and psychological interventions for the treatment of psychosis and schizophrenia in children, adolescents and young adults: A systematic review and meta-analysis. Public Library of Science 10 (2), e0117166.

Tor, J., Dolz, M., Sintes, A., Muñoz, D., Pardo, M., de la Serna, E., et al., 2017. Clinical high risk for psychosis in children and adolescents: a systematic review. European Child and Adolescent Psychiatry 27 (6), 683-700. https://doi.org /10.1007/s00787017-1046-3.

Tsai, K.H., Lopez, S., Marvin, S., Zinberg, J., Cannon, T.D., O'Brien, M., et al., 2015. Perceptions of family criticism and warmth and their link to symptom expression in racially/ethnically diverse adolescents and young adults at clinical high risk for psychosis. Early Intervention in Psychiatry 9 (6), 476-486.

Welsh, P., Tiffin, P.A., 2015. Adolescent family perceptions in the At-Risk Mental State for psychosis. Early Intervention in Psychiatry 9 (4), 316-323.

Wang, X., Chen, Q., Yang, M., 2017. Effect of caregivers' expressed emotion on the care burden and rehospitalization rate of schizophrenia. Patient Preference and Adherence 11, 1505-1511. http://doi.org/10.2147/PPA.S143873.

Wong, C., Davidson, L., McGlashan, T., Gerson, R., Malaspina, D., Corcoran, C., 2008. Comparable family burden in families of clinical high-risk and recent-onset psychosis patients. Early Intervention in Psychiatry 2 (4) 256-261. 
Table 2: Summary of the fifteen included studies looking at Expressed Emotion (EE) in the ARMS population

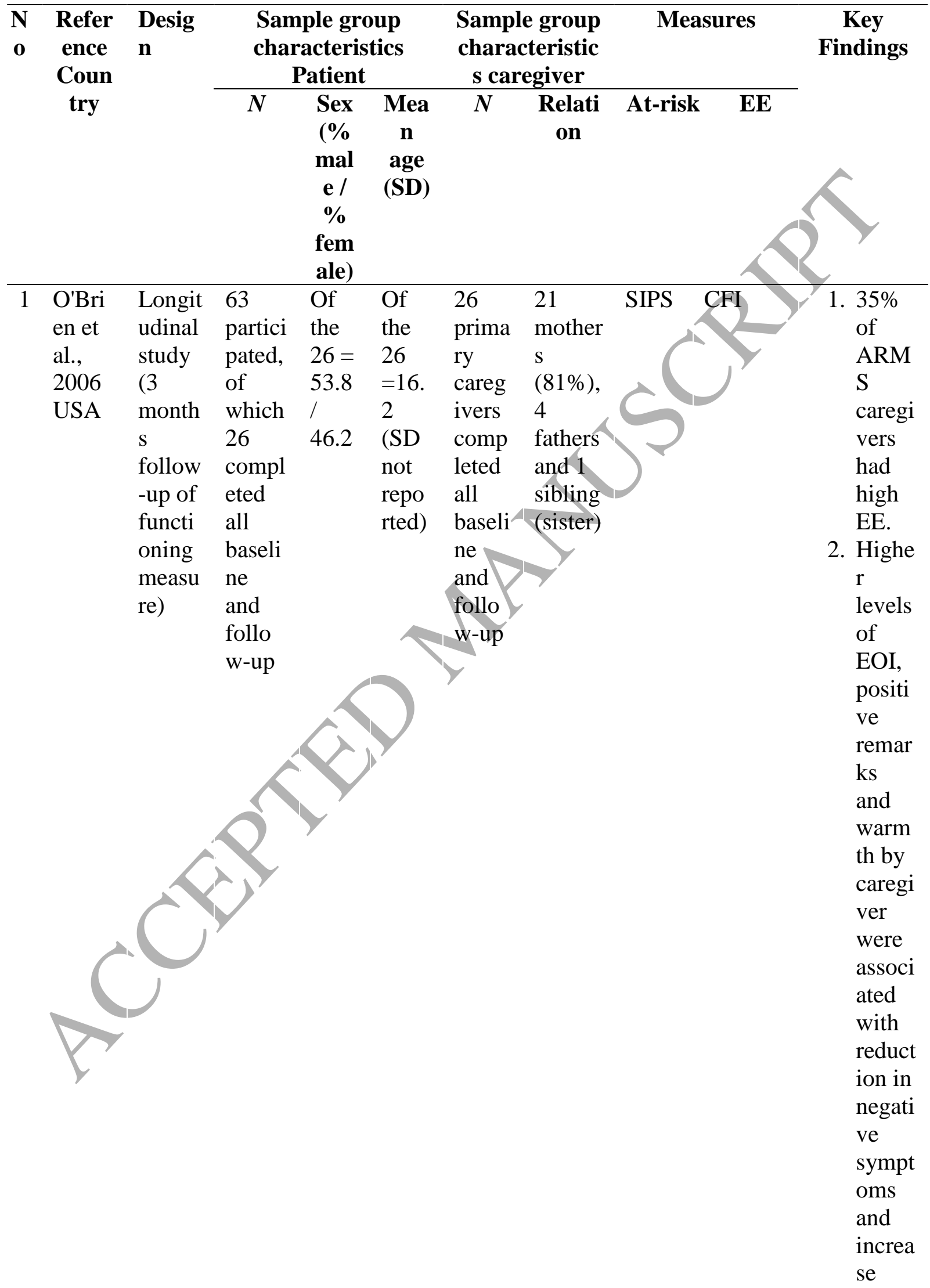


social

functi

oning

at 3

mont

hs.

3. $39 \%$

of the

overal

1

comm

ents

were

critica

1 and

direct

ed at

the

young

peopl

e's

negati

ve

sympt

oms,

irritab

ility

or

aggre

ssion.

4. There

was

no

associ

ation

betwe

en

critica

1

comm

ents

and

chang

es in

functi

oning

or

sympt

oms.

$2 \mathrm{McFa}$ Cross In Sam Sam Total Mothe SIPS SAS-III 1. EE 
rlane sectio total ple 1 ple 1 in rs and nal $119==$ ARM (44), Cook, $\quad($ Sam $68.0 \quad 31.0 ; \quad S=$ fathers 2007 ple 1 / Sam 78

USA $=31 \quad 32.0 ;$ ple 2 $(68 \%$ Sam =

SZ, ple 2 34.0; $32 \%=\mathrm{AR}$ $\operatorname{mood} 64.0$ MS

was signif icantl $\mathrm{y}$ highe $r$ in establ ished disord / = 16 SZ

er), 36.0; (SD and

Sampl AR not

e $2=$ MS repo

33 grou rted)

$(64 \% \mathrm{p}=$

SZ, 56.0/

$35 \% \quad 44.0$

mood

disord

er),

Sampl

e $3=$

50

ARM

S)

mood

disord

er

famili

es

comp ared

to

ARM

$\mathrm{S}$

famili

es.

2. They

found the longe $r$ the durati on of untrea ted illnes $\mathrm{s}$, the highe $r$ the levels of $\mathrm{EE}$ in the ARM $\mathrm{S}$ popul ation.

3. Both mothe rs and father $s$ of ARM $\mathrm{S}$ indivi 
duals

were

warm

er,

less

rejecti

ng,

more

protec

tive

and

less

fused

with

their

child

comp

ared

to

establ

ished

psych

osis.

3 O'Bri Longit Baseli Base Base 40 32 SIPS CFI en et udinal ne $=$ line line $=$ prima mother

al., study $40 .=15.7$ ry $\mathrm{s}$ and 8

. Careg ivers

who

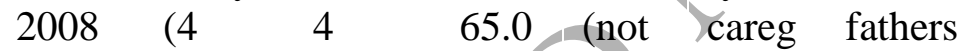

provi

USA month month / repo ivers ded

s follo 35.0 rted) more

follow w-up 4 positi

-up $=32$ mon mont ve

after th $\mathrm{h}$ remar

baseli follo follo ks

ne of $\lambda y$ w- w-up

clinica up not

were

more

likely

1 and, not repo

to

exhibi

rted

$\mathrm{t}$

constr

uctive

behav

iour

durin

$\mathrm{g}$ the

FIT.

2. Careg

ivers

who 


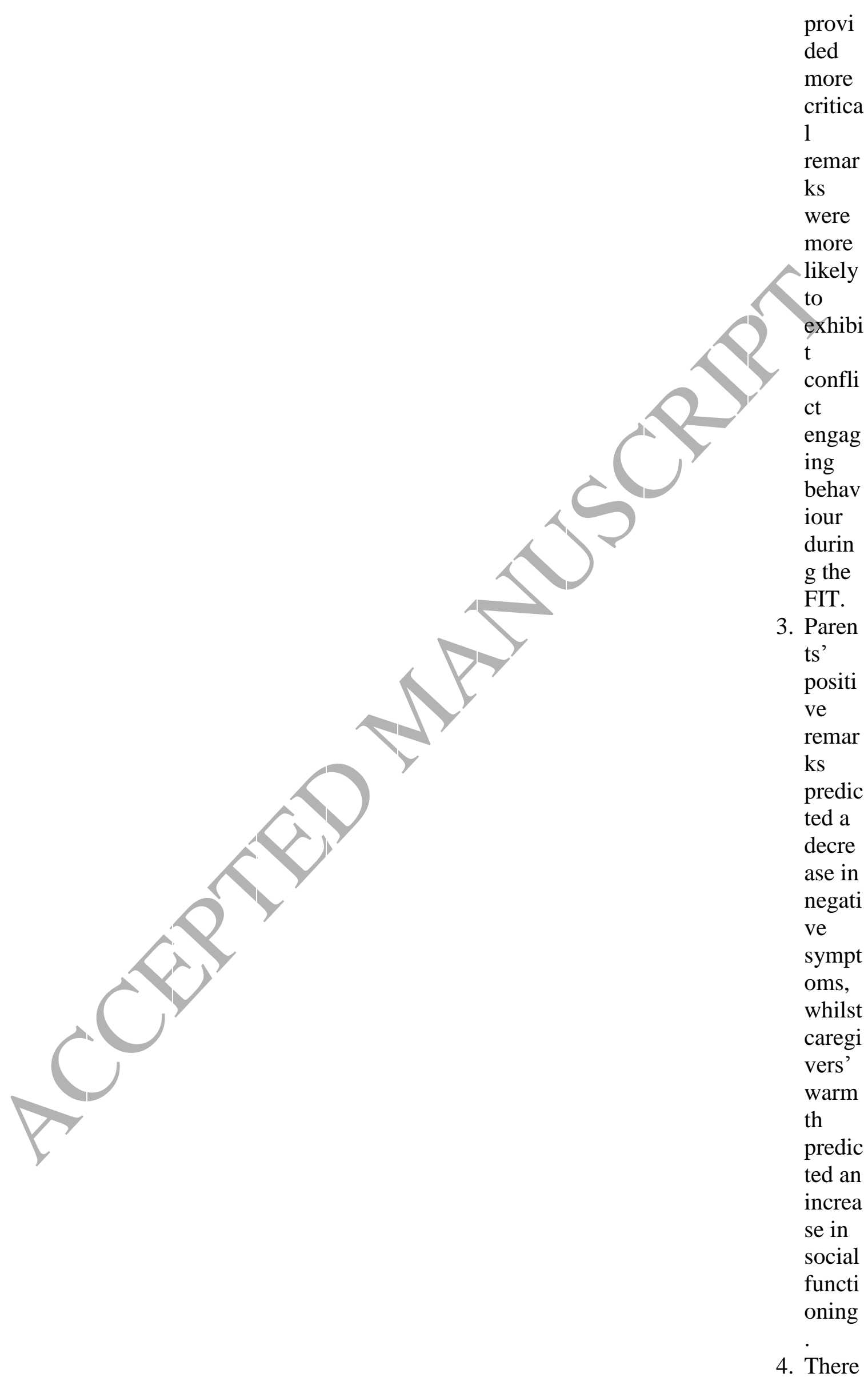




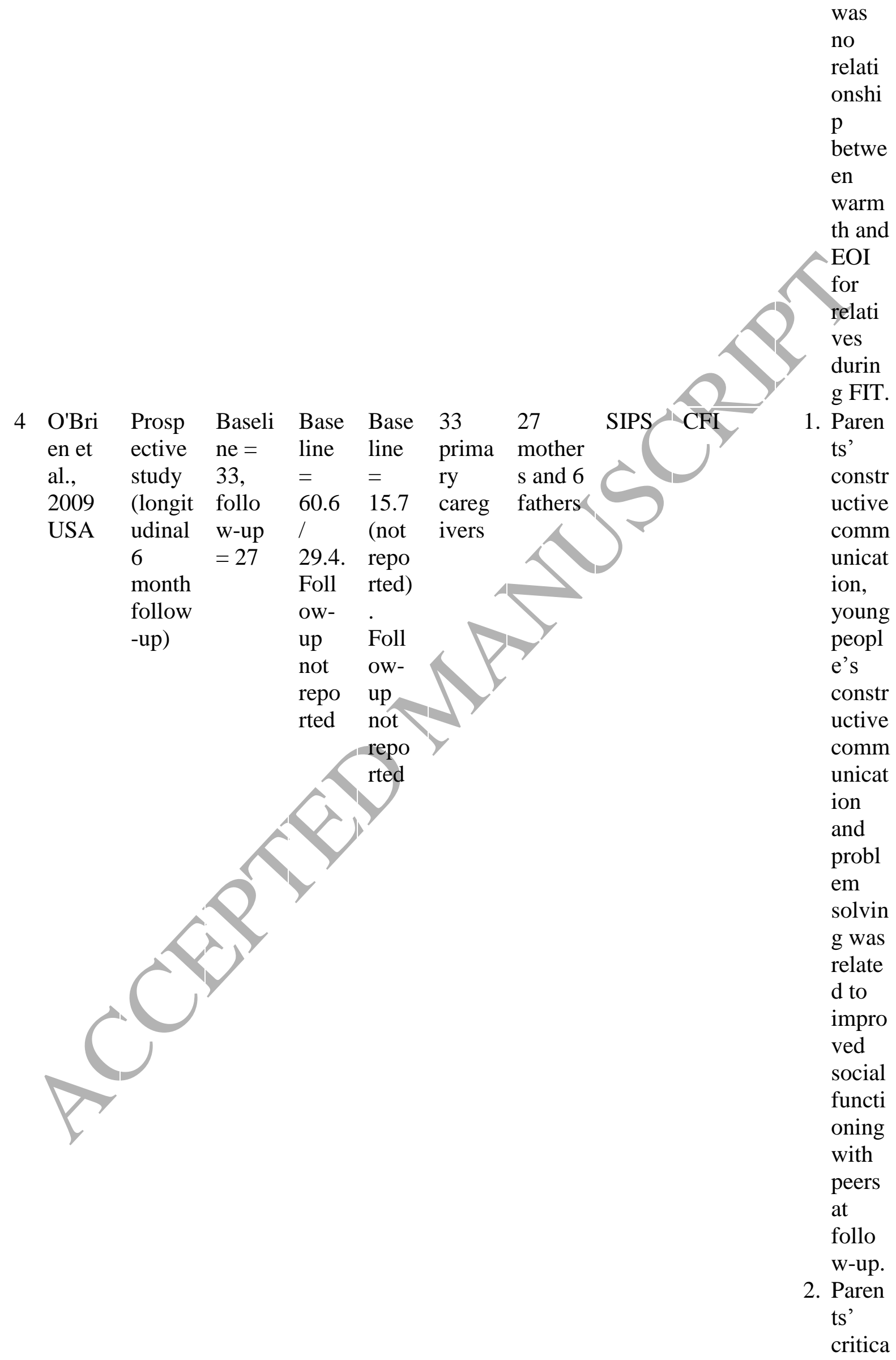




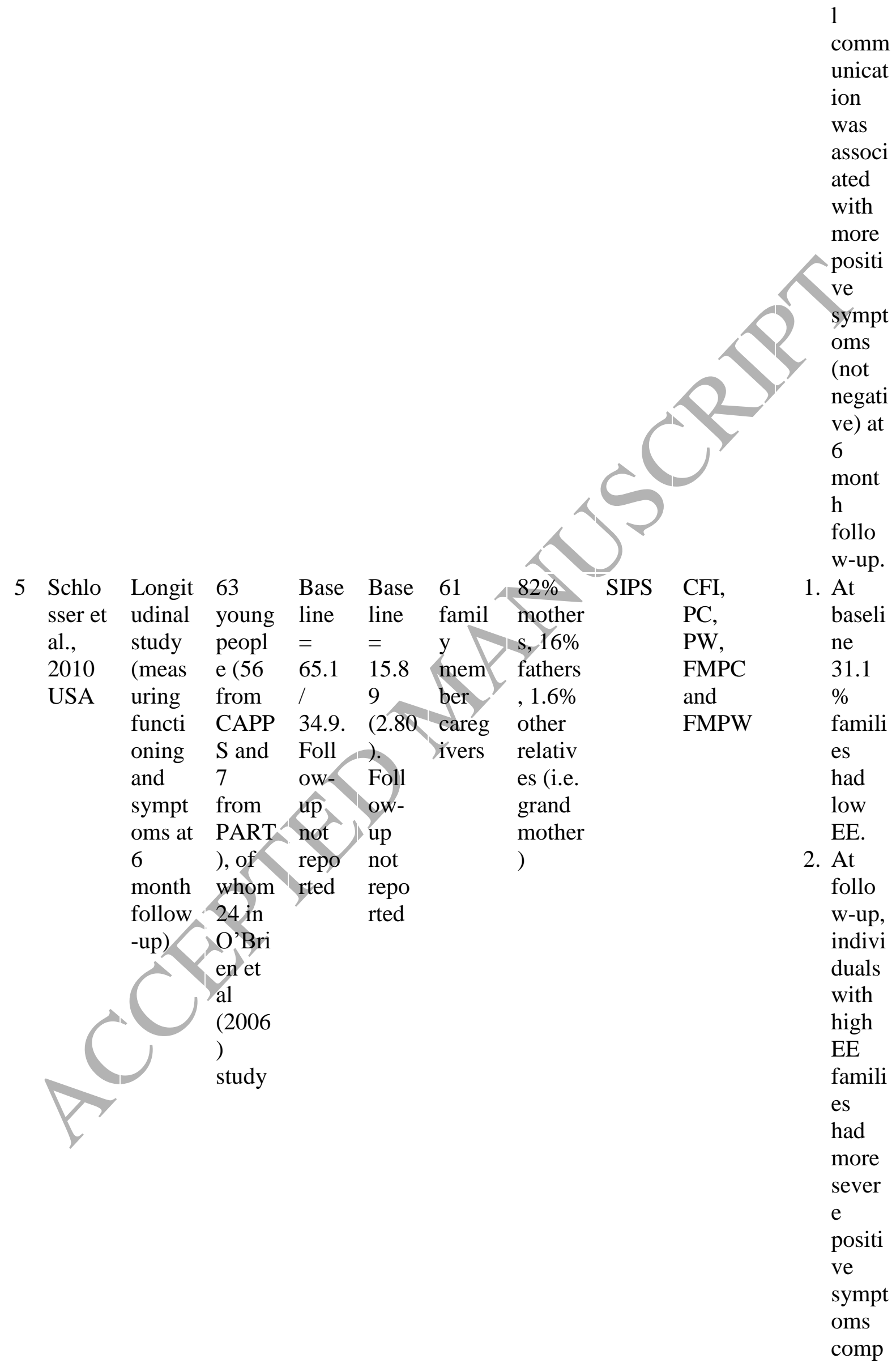


ared

to

low

EE

famili

es.

3. They

found

a

protec

tive

effect

from

warm

th and

optim

al

EOI

on

functi

oning

at 6

mont

hs.

4. FMP

W

negati

vely

relate

d to

object

ive

meas

ure of

critici

sm

and

positi

vely

relate

$d$ to

object

ive

meas

ure of

warm

th.

6 Mene Cross Total AR AR Total ARMS Met CFI ghelli, sectio $=143$ MS MS $=199$ mother $P A C$

1. One

third 


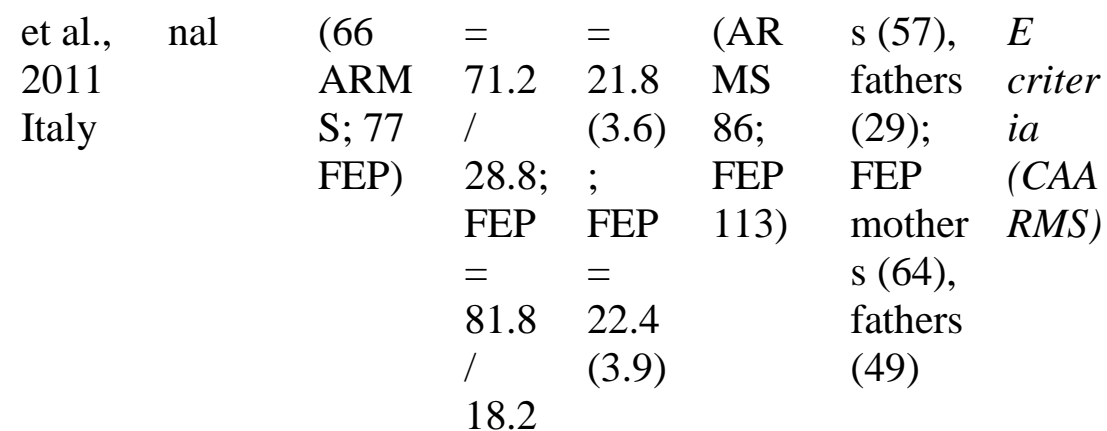

of

ARM

$S$ and

FEP

famili

es

had

high

EE,

mostl

y due

to

EOI.

2. ARM

$S$

famili

es

with

highe

r EE

typica

lly

includ

ed

young

er

indivi

duals,

who

were

more

likely

to

live

with

the

caregi

ver

and

have

highe

$\mathrm{r}$

conta

ct.

3. DUI

not

relate

d to

high

$\mathrm{EE}$ in 
ARM

S, but

was

in

FEP.

4. No

link

betwe

en

$\mathrm{EE}$,

severi

ty of

illnes

s and

psych

osoci

al

functi

oning

7 Domí Cross $44(20$ Over Over $44 \quad 65.9 \%$ CAA The FQ

1. Relati nguez sectio

$\mathrm{ARM} \quad$ all $=$ all $(20$ female RMS

ves'

Martí nal

S, 24 65.9 mea

ARM relativ FEP) / $\mathrm{n}$

S, 24 es of

34.1 age FEP) whom

$\begin{array}{lll}= & 59.1 \% \\ 23.7 & \text { mother }\end{array}$

$\mathrm{EE}$

nez et

al.,

2014

(5.6)

s.

Other

relativ

es

includ

ed

fathers

(27.3

$\%$ ),

partner

$\mathrm{s}$

(9.1\%)

and

(both

ARM

$S$ and

FEP)

was

associ

ated

with

patien

ts'

sympt

oms

and

impai

red

functi

sibling

$\mathrm{s}$

(4.5\%)

oning

2. For

ARM

$\mathrm{S}$

caregi

vers,

high

EOI

was

signif 


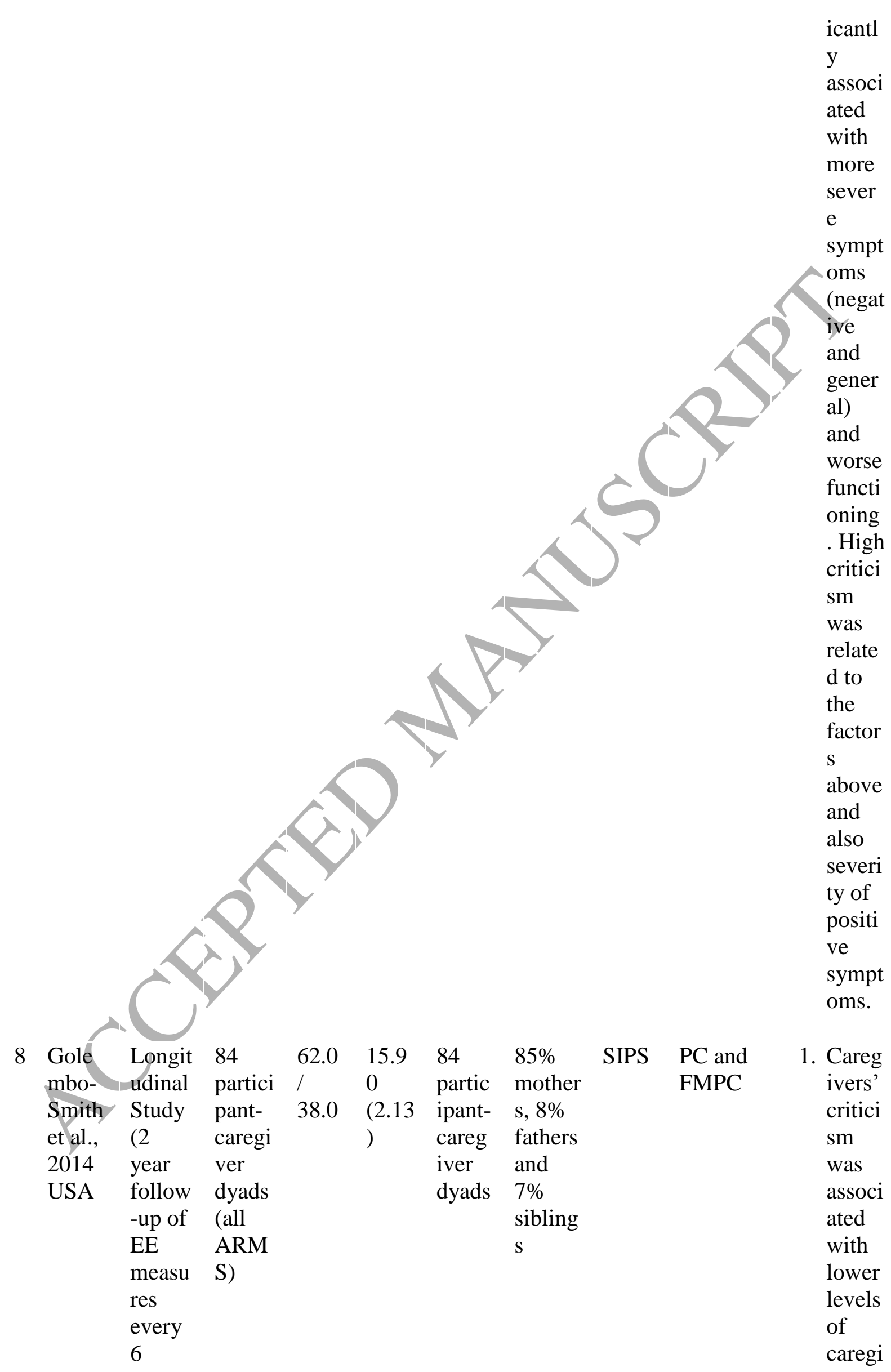


month

$\mathrm{s}$ for 2

ver-

years)

youth

agree

ment

(not

signif

icant)

whilst

sympt

om

severi

ty

was

not

relate

d to

agree

ment.

9 Carol Cross $79(37$ AR AR 43

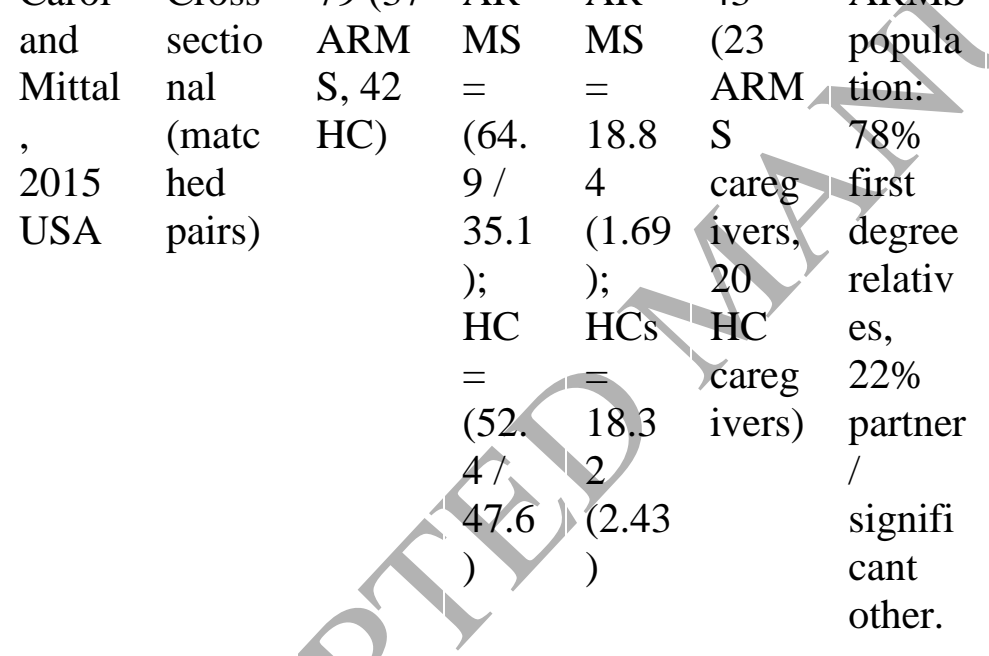

1. Signif icant

differ

ence

in $\mathrm{EE}$

betwe

en

relati

ves of

ARM

$S$ and

HCs.

2. ARM

$\mathrm{S}$

adole

scents

had

increa

sed

negati

ve

self-

conce

pt and

their

caregi

vers

provi

ded

signif

icantl 


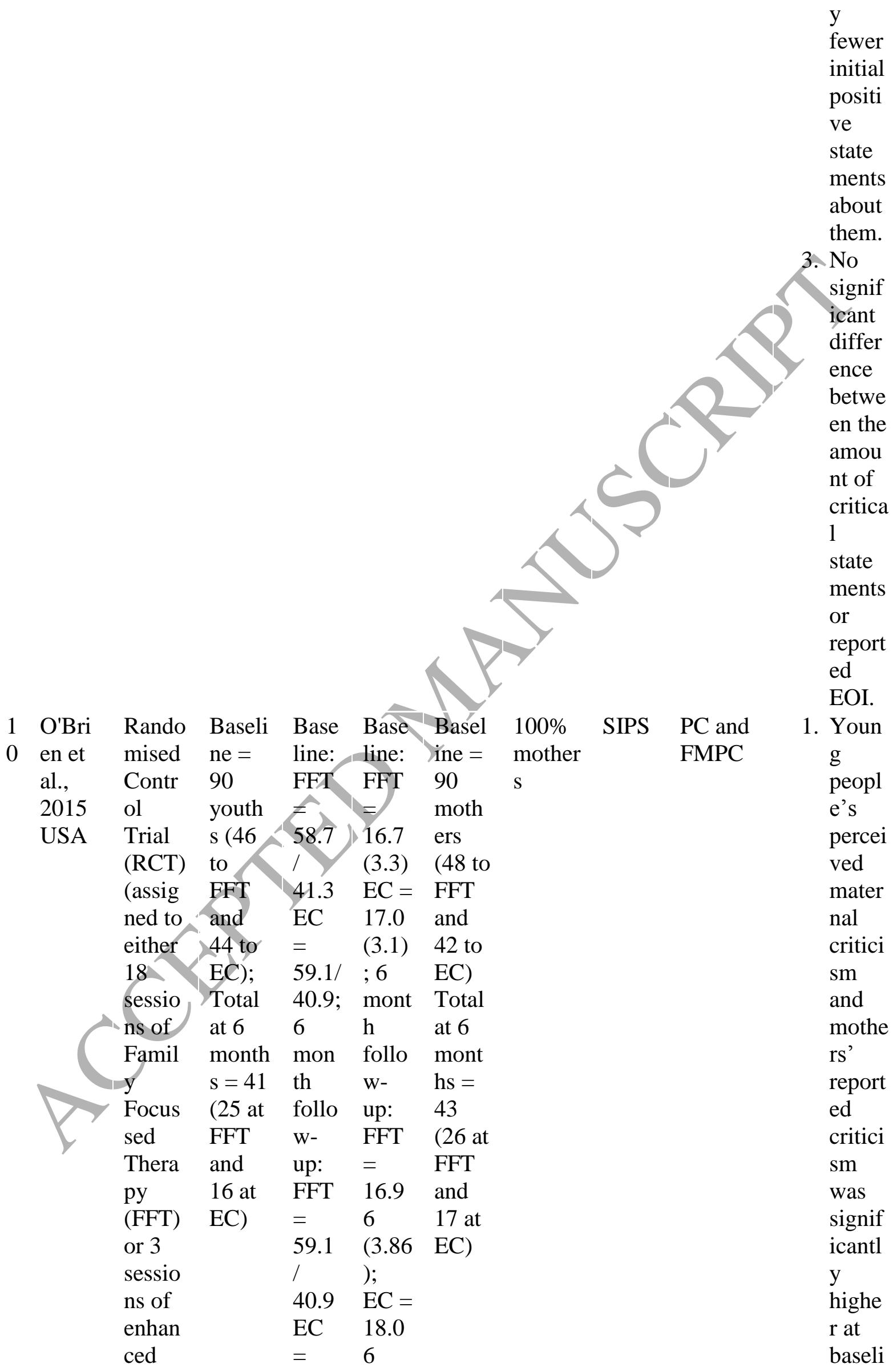


care

60.7/ (3.69

ne

(EC)

$39.3 \quad)$

than 6

mont

hs for

both

group

s.

2. Chan ge in critici sm

predic ted impro veme nts in positi ve sympt oms at 12 mont $\mathrm{h}$ follo w-up.

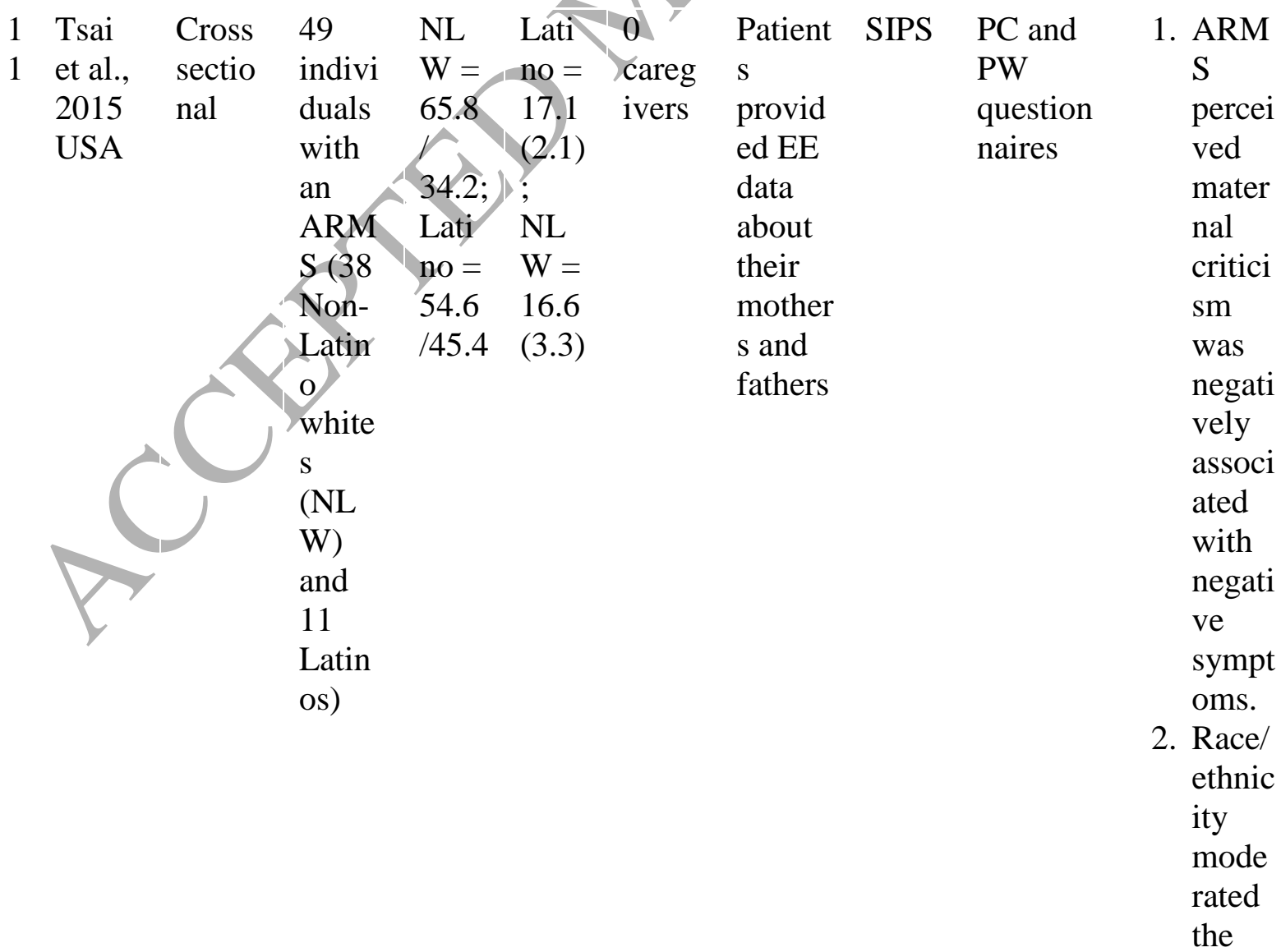


relati

onshi

$\mathrm{p}$

betwe

en

critici

$\mathrm{sm} / \mathrm{w}$

armth

and

ARM

$S$

sympt

omol

1 Welsh Cross Total AR AR 0 Patient CAA FPS

ogy.

2 and sectio $=210$ MS MS careg

Tiffin, nal $(44==$ ivers provid

2015

$\begin{array}{lll}\text { ARM } & 59.1 \quad 15.9\end{array}$

Engla

$\mathrm{S} ; 26 \quad / \quad$ (1.3)

psych 40.9; ;

otic; Psyc Psyc

140 hotic hosis

$\mathrm{HC}, \quad=\quad=$

health $57.6 \quad 16.3$

$\mathrm{y} \quad / \quad(1.1)$

contro 42.4; ;

1s) Cont $\mathrm{HC}$

rols $=$

$57.1(1.3)$

ed EE

data

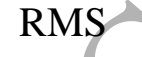

1. $\mathrm{EE}$

signif

icantl

y

highe

$r$ in

about

the

family

ARM

$S$ and

FEP

enviro

comp

ared

(caregi

ver

to

HC.

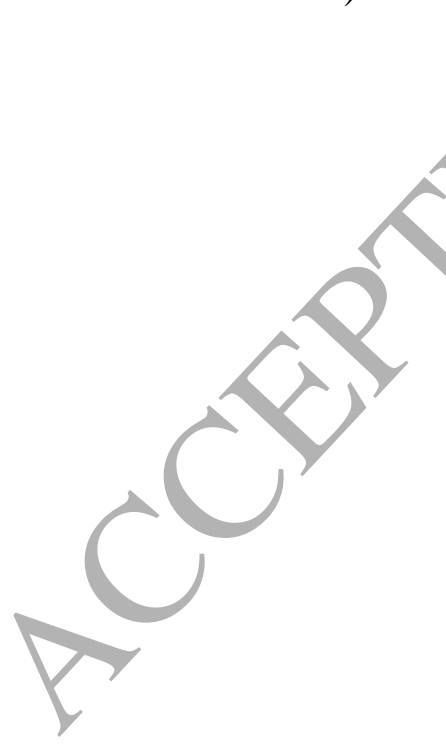

42.9

relatio

ns not

2. In

reporte

d)

comp

arison

to

FEP,

indivi

duals

with

ARM

$\mathrm{S}$

percei

ved

greate

$\mathrm{r}$

famil

$\mathrm{y}$

dysfu

nction

(not

signif

icant)

1 Hama Cross Total AR AR Total ARMS CAA Japanes 1. The 


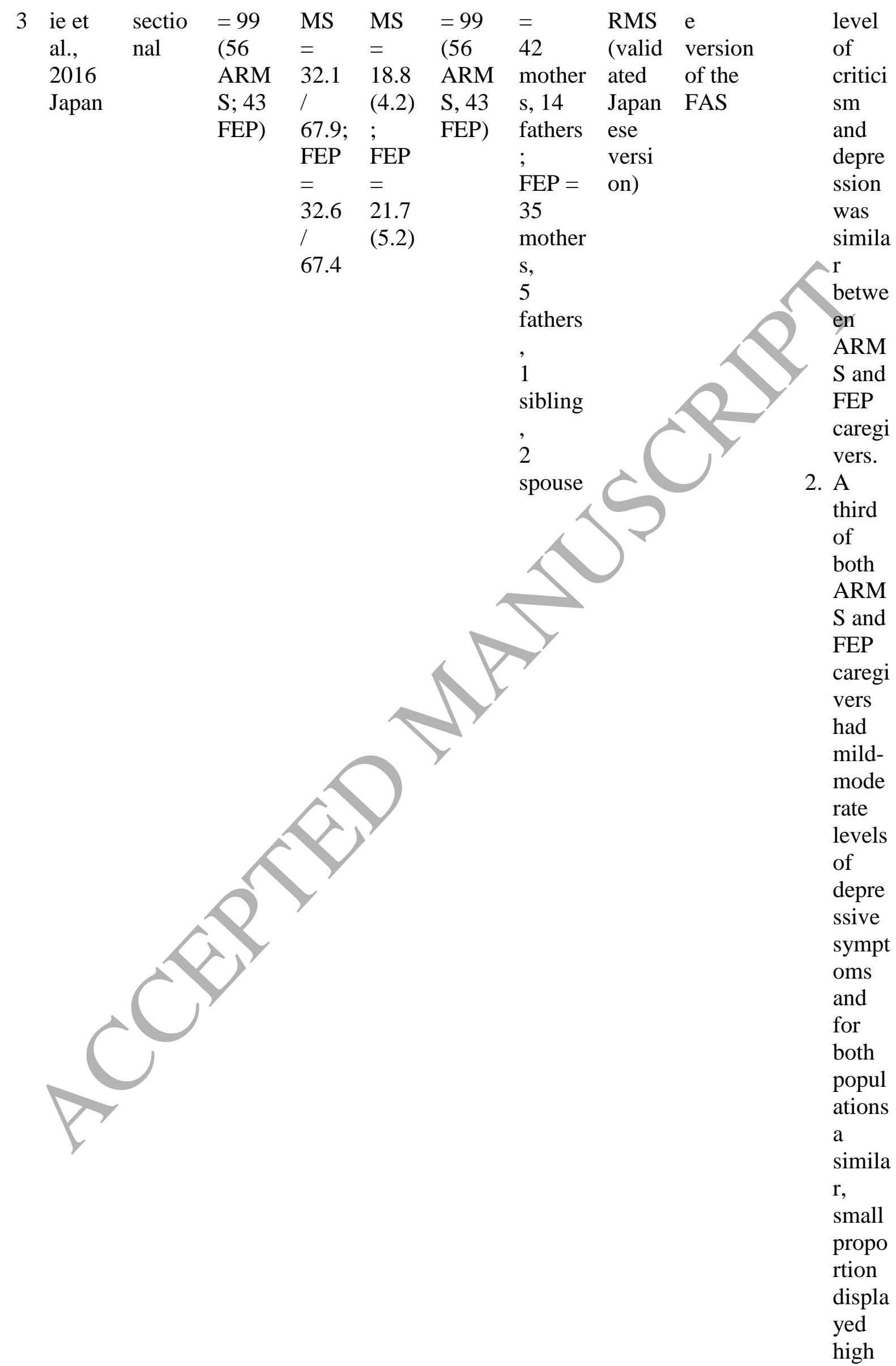


critici

sm.

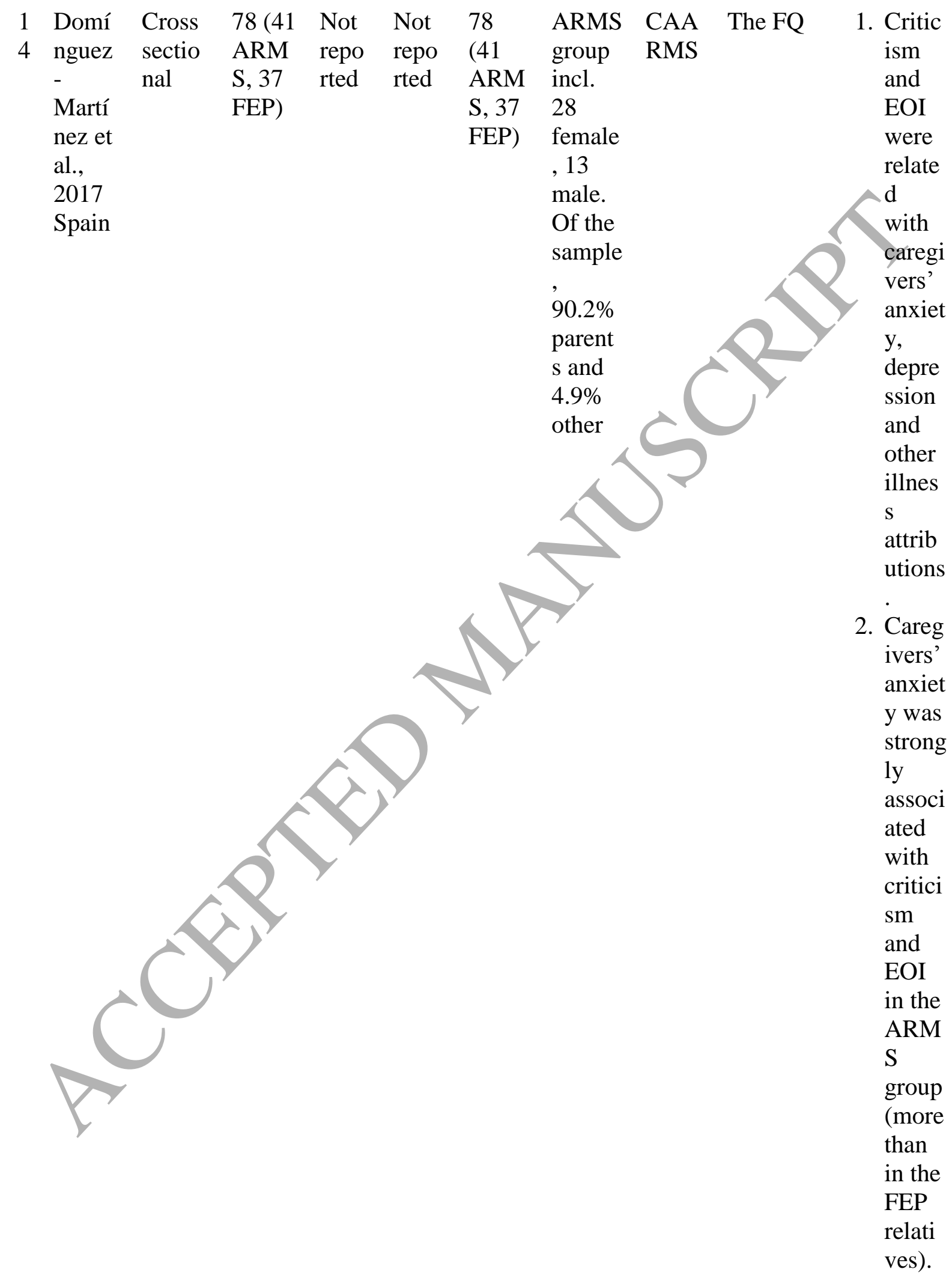

1 Haidl Natur Baseli Base Base 0 Patient SIPS LEE 1. Indivi

5 et al., alistic ne line line careg $\mathrm{s} \quad$ duals'




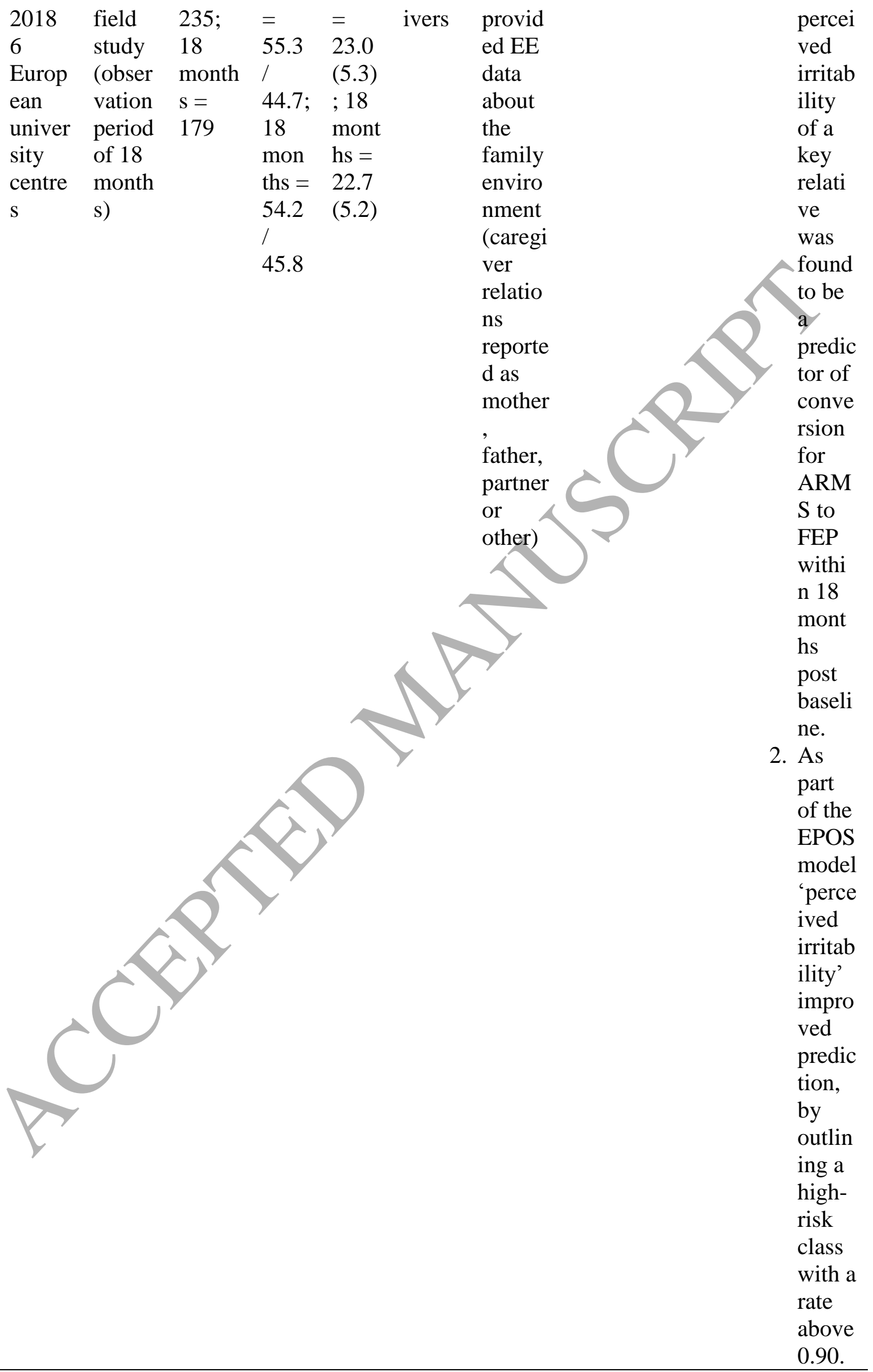


Abbreviations: ARMS: At Risk Mental State; HC: Healthy Controls; FEP: First Episode Psychosis; SZ: Schizophrenia; EE: Expressed Emotion; CAARMS: Comprehensive Assessment of At Risk Mental States; SIPS: Structured Interview for Prodromal Symptoms; FMSS: The Five Minute Speech Sample; The FQ: The Family Questionnaire; PC: Perceived Criticism Questionnaire; FMPC: Family Member Perceived Criticism Questionnaire; FAS: Family Attitude Scale; SAS-III: Social Adjusting Scale III; CFI: Camberwell Family Interview; LEE: Level of Expressed Emotion; PW: Perceived Warmth Questionnaire; FMPW: Family Member Perceived Warmth Questionnaire; FPS: Family Perception Scale.

A summary of the fifteen reviews containing demographic characteristics and key findings. The table aims to include the demographics of both the family members and the patients of which some were not reported. 
Table 3. Quality review of the included studies in chronological order

\begin{tabular}{lllllllllllllllllllllllll}
\hline Source & Ra & & ter & 1 & 2 & 3 & 4 & 5 & 6 & 7 & 8 & 9 & 1 & 1 & 1 & 1 & 1 & 1 & 1 & 1 & 1 & 1 & 2 & or \\
& & & & & & & & & & & & & 0 & 1 & 2 & 3 & 4 & 5 & 6 & 7 & 8 & 9 & 0 & e
\end{tabular}

1. O'Bri $\mathrm{A}++-++4-++++++-++++-+75$
en et
al.,

2006

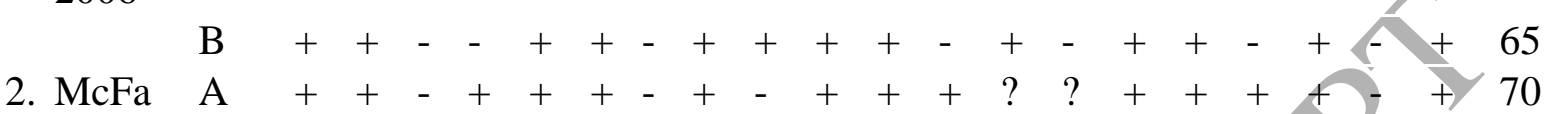
rlane

and

Cook,

2007

$\mathrm{B}+++-t_{-}+++-++-++1++-+70$

3. O'Bri $\mathrm{A}+++++--++-+?--++++-+65$ en et $\mathrm{B}++++++-++++$ ? ? ? ++ ? 70 al., 2008

4. O'Bri $\mathrm{A}++-+$ + $-++++++-{ }_{-}++++-+65$ en et al., 2009

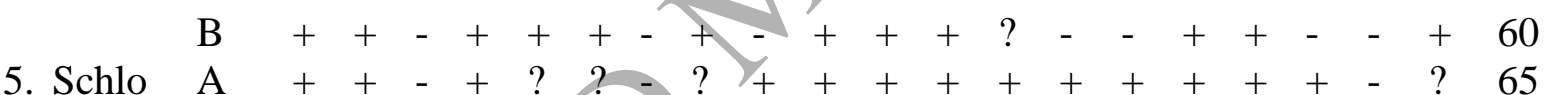
sser et al., 2010

6. Mene $\mathrm{A}++-+++-++++?++++++-+80$ ghelli et al., 2011

7. Domi A $++-++-?+++++--++++-+70$ nguez $\mathrm{A}+{ }_{+}++-++++++-+++++-+80$ Marti nez et al. 2014

8. Gole mboSmith et al., 2014 $\mathrm{B}++-+++++++++-+?+++-+80$

9. Carol $\mathrm{A}++-+++$ ? +++ ? ? ++++-+70 and 
Mittal

, 2015

$\begin{array}{rllllllllllllllllllllll} & \mathrm{B} & + & + & + & + & + & + & + & + & + & + & + & + & + & + & + & 75 \\ 10 . \mathrm{O} \text { Bri } & \mathrm{A} & + & + & + & + & + & ? & + & + & + & + & + & + & + & + & - & + & 85\end{array}$

en et al.,

2015

11. Tsai $\mathrm{A}++-+++-+++++--++++-+75$

et al., $\mathrm{B}++++++$ ? ++++ ? ? ? + ? + 70

2015

12. Wels

$\mathrm{A}+++++-t_{+}+++-t_{+}++++75$

$\mathrm{h}$ and

Tiffi

$\mathrm{n}$,

2015

13. Ham $\mathrm{A}++-+++++++++++++++-+90$

aie et $\mathrm{B}++++++$ ? +++++++++40 al.,

2016

14. Dom

$\mathrm{A}++-++$ ? +++++ ? ++++-+75 ingue

z-

Marti

nez

et al.,

2017

$\mathrm{B}++-++?-++++++++++-+75$

15. Haidl A ++-+++++++++-+++++++90 et al.,

2018

$\begin{array}{lllllllllllllllllllll}\text { Total (rater A } & 1 & 1 & 3 & 1 & 1 & 7 & 4 & 1 & 1 & 1 & 1 & 1 & 5 & 6 & 1 & 1 & 1 & 1 & 1 & 1\end{array}$ only)

$$
55
$$

53

$\begin{array}{lllll}3 & 4 & 4 & 5 & 2\end{array}$

$\begin{array}{lllll}5 & 5 & 5 & 5 & \end{array}$

Abbreviations: - the publication provided an informative description, but an inadequate performance; + , the publication provided an informative description of the criterion at issue and met the quality criterion; ?, the publication provided no or insufficient information; A, refers to rater number one; $\mathrm{B}$, refers to rater number two.

This table illustrates the similar scores of the paper quality assessed by two separate raters. The total score at the bottom of the table sums up the quality of each criterion from the fifteen papers included in the review; these criteria can be found in Downes et al., (2016) paper. Overall the papers included in the review had good quality and may have been missing information reported as opposed to the quality being poor. 